\title{
Internal corrosion and anticorrosion protection of offshore facilities in the presence of increased amounts of carbon dioxide
}

\author{
R.K. Vagapov, (1D* R.R. Kantyukov and D.N. Zapevalov \\ Gazprom VNIIGAZ LLC, 15 Proyektiruyemy proyezd 5537, bld. 1, Razvilka, Leninsky \\ municip., Moscow region, 142717, Russian Federation \\ *E-mail: $\underline{R}$ Vagapov@vniigaz.gazprom.ru
}

\begin{abstract}
Some operating and promising offshore hydrocarbon production facilities are characterized by an increased content of corrosive $\mathrm{CO}_{2}$ in the extracted products. The paper investigates the dynamic nature of the medium flow in the pipeline system at offshore facilities. To determine this factor, which has an intensifying effect on the internal corrosion processes, the shear stress was calculated taking into account the main operational parameters of such offshore fields. The authors compare several models for calculating the rate of internal corrosion with regard to the offshore gas field conditions. An empirically derived formula to assess the temperature and salinity impact on the corrosion rate resulting data is estimated. The paper analyzes comparability of the calculated results for different dependencies with the own corrosion rate data obtained during the gravimetric tests for the operating conditions of the offshore fields. Corrosion under moisture condensation conditions, which occurs at a temperature gradient and rapid cooling of the produced gas is most aggressive and dangerous. Tests show that the rate of local carbon dioxide corrosion can reach several $\mathrm{mm} / \mathrm{year}$. The authors estimate the severity of the influence of monoethylene glycol concentration used as a hydrate inhibitor in a water-glycol medium and its contribution into the corrosion rate, both in a liquid medium and during moisture condensation in the vapor phase. The presence of glycol can reduce corrosion in a liquid medium, but during moisture condensation, corrosion suppression is not influenced by the concentration of glycol in the evaporated liquid, but by its content in the liquid condensed on the steel surface.
\end{abstract}

Received: July 11, 2021. Published: August 18, 2021

doi: $\underline{10.17675 / 2305-6894-2021-10-3-17}$

Key words: carbon dioxide corrosion, offshore object facility, corrosion rate, inhibitory protection, local corrosion.

\section{Introduction}

The current conditions and prospects for the development of the resource base of hydrocarbon raw materials in Russia and globally are associated with fields, which products contain corrosive carbon dioxide $\left(\mathrm{CO}_{2}\right)$. Operation of field infrastructure facilities in such aggressive conditions implies corrosion problems that require corrosion protection measures to ensure their smooth and safe performance [1-4]. The danger of carbon dioxide corrosion 
(CDC) under such conditions can be typical of a number of offshore gas fields [5-7]. Subsea production units (SPU) at the Kirinskoye gas condensate field in the Sea of Okhotsk, the Ormen Lange, Snøhvit and other fields located on the Norwegian shelf represent successful cases [8-11].

The operation of offshore production facilities and pipeline transportation of untreated hydrocarbon products under CDC conditions has its own specifics and limitations compared to onshore fields. The challenges are related to treatment and transportation technologies for products with corrosive components, control of technological modes to minimize corrosive effects, the use and maintenance of means and systems for corrosion monitoring and the effectiveness of inhibitor protection against corrosion [7, 12].

The world experience in the operation of such facilities enable to evaluate the tasks and problems of their protection against internal corrosion. In [13], it is reported that up to 39\% of incidents on subsea pipelines in the Gulf of Mexico are corrosion-related: there are 4 times more corrosion defects due to internal corrosion than external.

As a rule, the work of the SPU is organized in such a way that the produced products from the wells are transported through a small-diameter flow line to the collecting manifold, from where, mixed it goes out in a single stream and is transported along the gas collector of large diameter located partly under water and partly on land underground. The produced hydrocarbons are transported to the onshore technological complex for processing and separation of gas and gas condensate.

Monoethylene glycol (MEG) is generally used to prevent hydrate formation during transportation of the extracted products at offshore facilities. The inhibitor of hydrate formation (regenerated) is supplied to the wells, and as it moves along the flow line and gas collector, it mixes with water reaching the unregenerated concentration. The initial concentration of regenerated MEG in water is $80-85 \%$. When it gets to the well product and is further transported through the pipeline, it is diluted with formation waters to lower concentrations (in an unregenerated form). In [14], based on the analysis of the foreign offshore facilities, it is noted that the minimum MEG content can reach approximately $40 \%$ in the liquid onshore at the end of the pipeline system. This may be due to increased water cut at the final operation stages. According to [15], the MEG content in the unregenerated fluid entering the onshore complex of the Kirinskoye field is 50-60\%. The specific features of MEG regeneration lead to the concentration and accumulation of mineral salts, which increases its corrosive activity.

\section{Results and Discussion}

It is known $[7,12]$ that corrosion can occur in a gas pipeline system:

- in the lower part of the pipe in the case of moisture accumulation (bottom-of-line corrosion, BOL);

- in the top of the pipe in case of moisture condensation (top-of-line corrosion TOL); 
- in places of moisture accumulation (cracks, gaps, stagnant zones, elevation differences, etc.).

The authors of [16] derived the corrosion rate reduction factors depending on the glycol content under BOL conditions. Results of our autoclave tests (static conditions) performed at elevated pressure and in a water model with a salinity of $23 \mathrm{~g} / \mathrm{dm}^{3}(\mathrm{MW})$, with a salinity of about $25 \mathrm{~g} / 1$ and in a $60 \%$ solution of MEG in MW confirmed that the corrosion rate decreases 3-3.5 times in MEG (60\%) compared to MW (Figure 1). We have carried out corrosion studies at $5-10^{\circ} \mathrm{C}$, to which the medium in the gas collector located in sea water can be cooled. It can be seen that when going from $10^{\circ} \mathrm{C}$ to $5^{\circ} \mathrm{C}$, a decrease in temperature leads to a decrease in the common corrosion rate $(K)$ by a factor of 1.6-2, both in MW (from 0.347 to $0.214 \mathrm{~mm} / \mathrm{year}$ ) and in a $60 \%$ MEG solution in MW (from 0.128 up to $0.066 \mathrm{~mm} /$ year).

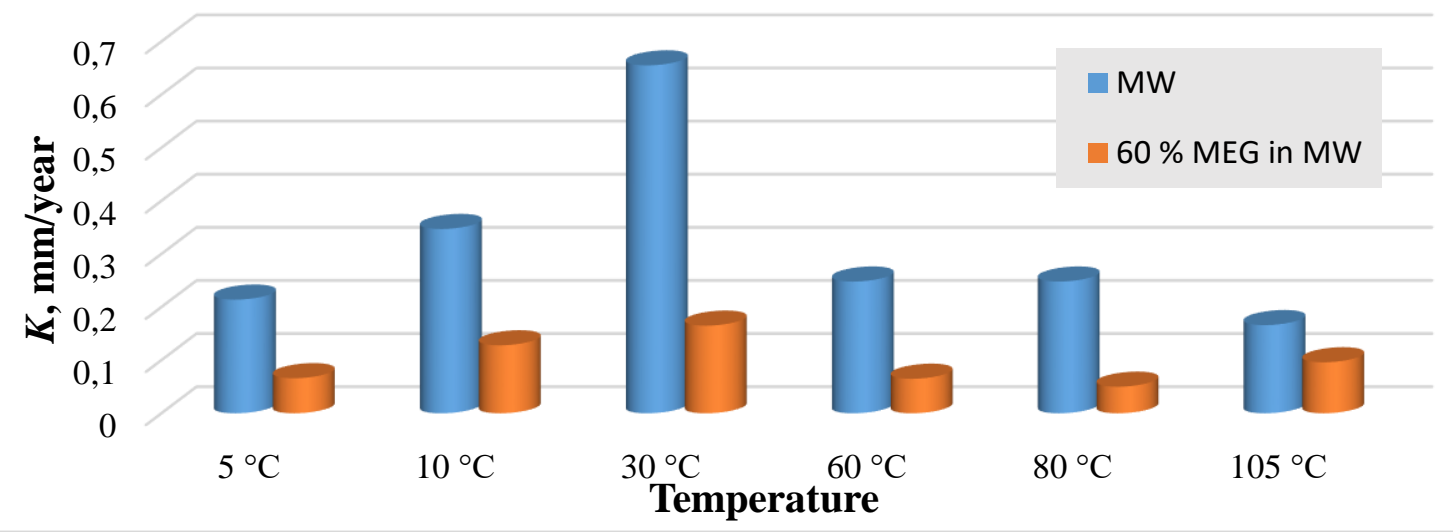

Figure 1. Dependence of the corrosion rate of samples of steel 20 on temperature in MW and in a $60 \%$ solution of MEG in $\mathrm{MW}$ at $P_{\mathrm{CO}_{2}}=0.8 \mathrm{MPa}$.

The results of laboratory tests (dynamic conditions) in the same water and water-glycol media of various concentrations [7] also confirm the relevance of the corrosion rate reduction factor depending on the MEG concentration. Corrosion rates in aqueous electrolyte, depending on the test method and temperature, reached up to $1.5-2.0 \mathrm{~mm} / \mathrm{year}$. With the addition of $25-50 \%$ of MEG to MW, the corrosion rate decreased and amounted to 30-60\% of the value obtained in identical tests in an environment in the absence of glycol.

Our linear polarization tests in water and water-glycol solutions have shown (Figure 2) that the decrease in the corrosion rate directly depends on the electrical conductivity $(\mathrm{G})$ of the medium, which is determined by the MEG concentration. The LPR (linear polarization probe) method used for measurements is different from the gravimetric one. The weight loss of the test element on the LPR during exposure to an aggressive environment is estimated based on the corrosion current measurement results of the steel probe.

Autoclave tests that we carried out under conditions identical to those in Figure 1 (at $60^{\circ} \mathrm{C}$ ) showed that alkalinization of the solution (up to $\mathrm{pH} 10$ at the beginning of the tests) 
leads to a multidirectional change in the corrosion rate. If alkali added into a MW water medium reduced the corrosion rate by $25 \%(0.185 \mathrm{~mm} / \mathrm{year})$ compared to the value in Figure $1(0.248 \mathrm{~mm} / \mathrm{year}$ ), then for a $60 \%$ solution of MEG in MW (with $\mathrm{pH}=10$ ) the corrosion rate increases 2 times (up to $0.127 \mathrm{~mm} / \mathrm{year}$ ). Such an increase is apparently associated with a decrease in the solubility of the components and precipitation in an alkaline water-glycol solution as compared to a neutral solution.

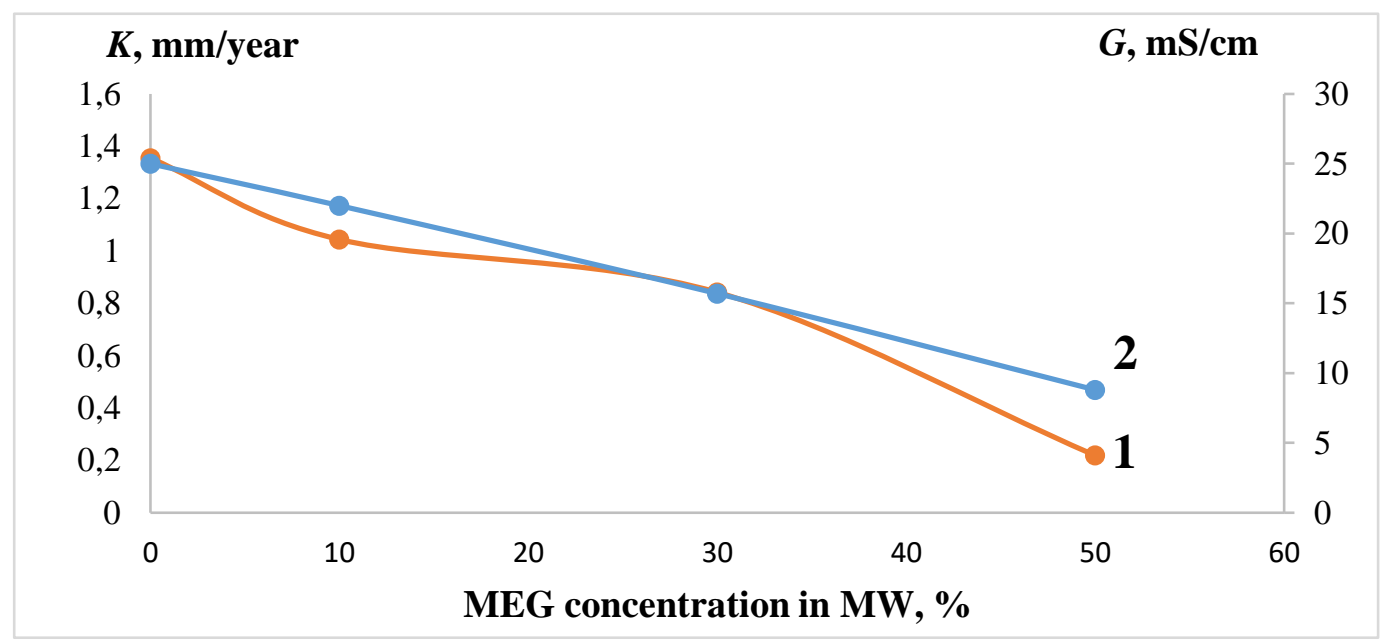

Figure 2. Dependence of the corrosion rate (1) and electrical conductivity (G) of the medium (2) on the MEG concentration in the tested medium MW.

Under such conditions, the use of corrosion inhibitors is one of the most effective methods to protect offshore facilities against CDC. This is confirmed by the Russian [7, 12] and foreign [17-21] studies. The results of comparative autoclave tests of the corrosion inhibitor in water and water-glycol media are presented in Table 1. One can see that the inhibitor protects steel 20 in water and water-glycol media, reducing the corrosion rate to $0.1 \mathrm{~mm} /$ year and below.

Table 1. The temperature dependence of the corrosion rate ( $\mathrm{mm} / \mathrm{year})$ of steel 20 in water and water-glycol in the presence of a corrosion inhibitor.

\begin{tabular}{cccccc}
\hline \multirow{2}{*}{ Medium } & \multicolumn{5}{c}{ Temperature, ${ }^{\circ} \mathbf{C}$} \\
\cline { 2 - 6 } & $\mathbf{5}$ & $\mathbf{3 0}$ & $\mathbf{6 0}$ & $\mathbf{8 0}$ & $\mathbf{1 0 0}$ \\
\hline MW & 0.009 & 0.035 & 0.055 & 0.1 & 0.095 \\
$60 \%$ MEG in MW & - & 0.036 & 0.076 & 0.078 & 0.065 \\
\hline
\end{tabular}

TOL corrosion is typical of gas fields, which is the main distinctive feature of the corrosive conditions present at gas and oil facilities. TOL corrosion in the presence of $\mathrm{CO}_{2}$ develops with the formation of local corrosion damage [22-27]. 
We have carried out tests under moisture condensation conditions in a MEG solution in $\mathrm{MW}$ in the presence of $\mathrm{CO}_{2}$. Local corrosion was determined by the depth of corrosion damage:

- average $\left(K_{\text {loc.av. }}\right)$ - by averaging all local defects;

- maximum $\left(K_{\text {loc.av. }}\right)$ - for the deepest local defect.

Various samples of carbon steels were used for testing: steel 20 and steel, which is used in the production of tubing (J55LT). The temperature difference between the air environment $\left(20-25^{\circ} \mathrm{C}\right)$ and the artificially cooled steel surface $\left(10^{\circ} \mathrm{C}\right)$ reached up to $10-15^{\circ} \mathrm{C}$.

General corrosion rates calculated from weight loss were below $0.1 \mathrm{~mm} / \mathrm{year}$ in all tests. But the samples showed local corrosion damage in the form of pits, which depth was the basis to calculate the real local corrosion. Table 2 shows the local TOL corrosion values for two steels (steel 20 and J55LT). It can be seen that CDC localization takes place at 55-65\% MEG solutions in MW: the local corrosion rate reaches up to $0.3-0.7 \mathrm{~mm} /$ year depending on the steel grade.

Table 2. Local corrosion rates calculated based on the depth of corrosion damage.

\begin{tabular}{|c|c|c|c|c|c|}
\hline \multirow{2}{*}{ Steel grade } & \multirow{2}{*}{$\begin{array}{l}\text { Sample } \\
\text { No. }\end{array}$} & \multicolumn{2}{|c|}{$\begin{array}{l}\text { Depth of corrosion } \\
\text { damage, mcm }\end{array}$} & \multicolumn{2}{|c|}{ Local corrosion rates, $\mathrm{mm} /$ year } \\
\hline & & average & maximum & Kloc.av. & $K_{\text {loc.max. }}$ \\
\hline \multicolumn{6}{|c|}{$55 \%$ MEG in MW } \\
\hline \multirow{2}{*}{ Steel 20} & 11 & 23 & 28 & 0.300 & 0.365 \\
\hline & 12 & 25 & 31 & 0.326 & 0.404 \\
\hline \multirow{2}{*}{ J55LT } & 15 & 21 & 24 & 0.274 & 0.313 \\
\hline & 16 & 36 & 54 & 0.469 & 0.704 \\
\hline \multicolumn{6}{|c|}{$65 \%$ solution MEG in MW } \\
\hline \multirow{3}{*}{ Steel 20} & 11 & 30 & 40 & 0.391 & 0.521 \\
\hline & 12 & 26 & 46 & 0.339 & 0.600 \\
\hline & 13 & 25 & 29 & 0.326 & 0.378 \\
\hline \multirow{3}{*}{ J55LT } & 14 & 28 & 40 & 0.365 & 0.521 \\
\hline & 15 & 33 & 45 & 0.430 & 0.587 \\
\hline & 16 & 28 & 36 & 0.365 & 0.469 \\
\hline
\end{tabular}

Test data show $[14,28]$ that under TOL conditions glycol does not have a high corrosion-reducing effect (up to $0.1 \mathrm{~mm} /$ year and below) as long as the MEG content in the evaporated liquid is lower than 70-80\%. The inhibitory effect of glycol is associated with the fact that upon going from $70 \%$ to $80-90 \%$ MEG solution in water an increase from 
$7-8 \%$ to $53 \%$ of the MEG content in water condensed on the steel surface occurs [14]. When testing steels at a higher concentration of MEG in a water-glycol solution (85\%) in the presence of $\mathrm{CO}_{2}$, local corrosion is not observed, and corrosion products are not formed (Table 3). The increased concentration of MEG ensures the protection of steel from CDC: the amount of water is insufficient for the development of CDC. To compare Table 4 shows steel samples after tests in a 50\% MEG solution before and after removal of corrosion products on steel, under which pits are observed.

Table 3. Post-test steel samples under condensation of a water-glycol mixture and in the presence of $\mathrm{CO}_{2}$ as per [28].

$\begin{array}{ccc}\text { Concentration of MEG, } \% \quad \text { Witn corrosion products } & \begin{array}{c}\text { After removing of corrosion } \\ \text { products }\end{array}\end{array}$

50
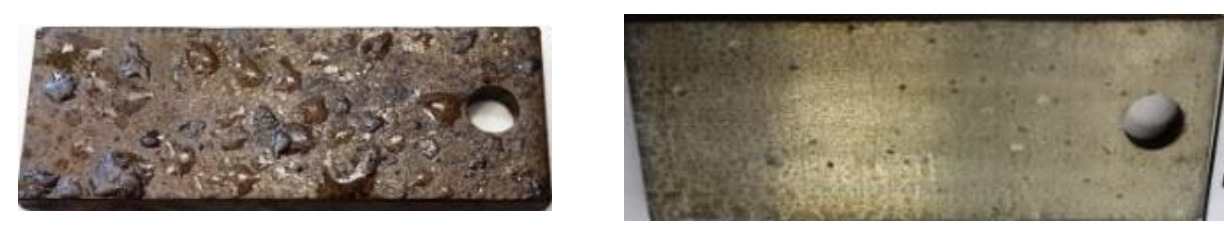

85
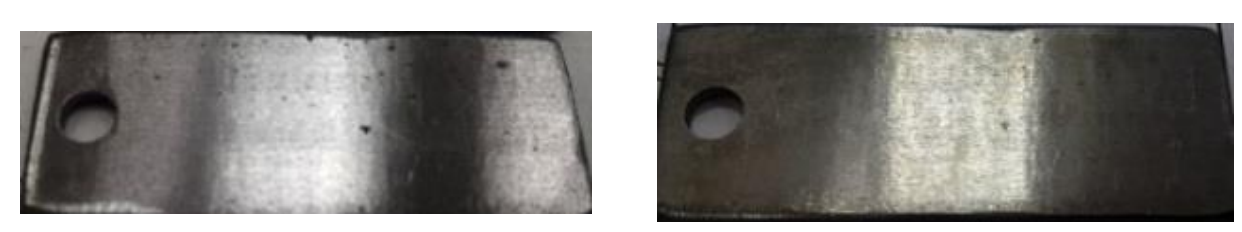

One of the corrosion intensification factors is the dynamic nature of the hydrocarbon raw materials flow in the pipeline system at production facilities. Corrosion studies use a wall shear stress to consider the medium movement rate and its effect on the inner surface of the pipe metal [29].

The main flow factors that affect corrosion are as follows:

- before corrosion products layer is formed, the main role of the turbulent flow is to enhance the supply and transfer of corrosive components to the pipe metal surface, which can lead to an increase in the corrosion rate;

- when corrosive deposits form on the metal, the flow can facilitate the removal of corrosion products with a porous structure and low adhesion to the metal surface, which can also lead to the activation of the corrosion process (its maintenance or increase).

If a corrosion inhibitor is used to protect the inner surface of pipelines, the flow can affect the adsorption of the corrosion inhibitor on steel and the inhibitor layer retains its filmforming properties.

We carried out a comparative analysis of the operating conditions of a number of offshore facilities (Kirinskoye field, Ormen Lange, Snøhvit) to systematize the main 
offshore corrosion factors (Table 4). Obtained data were used to calculate the shear stress typical for offshore conditions (Table 4). These data were taken as a basis and adopted for predictive assessment of the corrosion rate and comparison of various corrosion forecast models.

Table 4. Shear stress and the initial values used in calculations.

\begin{tabular}{|c|c|c|}
\hline Initial values & Flow line & Gas collector \\
\hline Gas flow rate, $\mathrm{mln}^{3} /$ day & $1.6-2.0$ & $4-5$ \\
\hline Liquid flow rate, $t /$ day & $320-400$ & $780-980$ \\
\hline Pipe diameter (internal), mm & $240-300$ & $450-500$ \\
\hline Pressure, MPa & 10 & $9-10$ \\
\hline Temperature, ${ }^{\circ} \mathrm{C}$ & $18-70$ & $3-30$ \\
\hline Content of $\mathrm{CO}_{2}, \%$ & & \\
\hline Mineralization, $\mathrm{g} / \mathrm{cm}^{3}$ & & \\
\hline Content of $\mathrm{C}_{5+}, \mathrm{g} / \mathrm{m}^{3}$ & & \\
\hline Content of water (per $1 \mathrm{~m}^{3}$ of gas), $\mathrm{g}$ & & \\
\hline Shear stress, $\mathrm{Pa}$ & - & - \\
\hline method 1 & $5.2-13.9$ & $1.0-36.0$ \\
\hline method 2 & $28.5-115.2$ & $4.7-212.5$ \\
\hline method 3 & $4.6-18.8$ & $1.1-50.2$ \\
\hline
\end{tabular}

When calculating the shear stress $(\tau)$ for oil and gas facilities, the following equation is generally used [30]:

$$
\tau=\frac{\rho \cdot f \cdot v^{2}}{2}
$$

Where:

$v$ - flow rate, $\mathrm{m} / \mathrm{s}$

$\rho-$ density, $\mathrm{kg} / \mathrm{m}^{3}$

$f$ - friction factor.

However, formula (1) is applicable for oil fields and transport conditions through pipelines completely filled with water-oil liquid.

For gas-liquid transport typical for gas production facilities, when most of the pipe section is filled with gas, it is recommended [31] to calculate the shear stress according to the equation:

$$
\tau=0.125 \cdot \rho \cdot f \cdot v^{2}
$$


The content of the liquid flow in a gas pipeline is significantly lower than in an oil pipeline. Therefore, the impact of the shear stress on the metal surface corrosion is different. Further calculations were carried out according to the formula (2).

As formulae (1) and (2) show, density of the medium, the flow rate and the friction factor are used to calculate the shear stress in the pipeline.

Several methods are used to calculate the of friction factor:

- as per NORSOK standard M-506 (method 1) [32];

- as per authors' recommendation [33] using the Moody diagram, relative roughness, Reynolds number and dynamic viscosity of the fluid [29, 34], (method 2);

- as per recommendation [35] (method 3).

Table 5 shows the results of calculating shear stresses using the friction factor found by three different methods. It stands to mention that shear stress values, and the corresponding friction factors calculated using methods 1 and 3 have similar values. Calculations according to method 2 give 5 times higher shear stresses.

The [36] states that as per calculations the shear stress was mainly in the range of 3.6-8.4 $\mathrm{Pa}$ and did not exceed $25 \mathrm{~Pa}$ for similar offshore pipeline transport conditions $\left(P_{\mathrm{CO}_{2}}=0.39-2.48 \mathrm{MPa}\right)$.

There are various models for calculating the predicted corrosion rates (CR) based on the main field corrosion hazard factors [37]. We have used several of them, including those using shear stress in assessing the corrosion rate of the medium. The operating conditions for offshore fields were taken from Table 4.

The authors of [38] propose the following equation to determine the rate of CDC:

$$
\mathrm{CR}=416649 \cdot T \cdot e^{\left(-\frac{5041}{T}\right)} \cdot P_{\mathrm{CO}_{2}}^{c}
$$

Where:

$P_{\mathrm{CO}_{2}}$ - partial pressure of $\mathrm{CO}_{2}, \mathrm{MPa}$;

$c$ - factor for partial pressure of $\mathrm{CO}_{2}, 0.83 \pm 0.07$ as per [38];

$T$ - temperature, $\mathrm{K}$;

$b$ - shear stress factor 0.11 as per [38].

NORSOK standard M-506 [32] provides another frequently used formula for calculating the rate of CDC. It takes different forms depending on the temperature of the medium.

At temperatures close to $20^{\circ} \mathrm{C}$ and higher the following equation is applied:

$$
\mathrm{CR}=k_{\mathrm{t}} \cdot 0.62 \cdot \frac{\tau}{19} \cdot 0.146+0.0324 \cdot \log \left(f_{\mathrm{CO}_{2}}\right) \cdot f(\mathrm{pH})_{\mathrm{t}}
$$

Where:

$f$ - parameters factor; 
$k$ - temperature ratio.

As per [32], at temperatures of $5^{\circ} \mathrm{C}$ and below, corrosion depends only on the partial pressure of $\mathrm{CO}_{2}$, temperature and $\mathrm{pH}$ of the medium. Thus, the equation for the $\mathrm{CDC}$ rate has the following form:

$$
\mathrm{CR}=k_{\mathrm{t}} \cdot f_{\mathrm{CO}_{2}} \cdot 0.36 \cdot f(\mathrm{pH})_{\mathrm{t}}
$$

There is another widely used method proposed by de Ward and Milliams [39] to calculate $\mathrm{CDC}$ rate in addition to the above mentioned equations. This approach takes into account the dependence of the $\mathrm{CDC}$ rate on the temperature of the medium and $\mathrm{CO}_{2}$ partial pressure, but does not consider the influence of the shear stress:

$$
\log \mathrm{CR}=5.8-\frac{1710}{273+T}+0.67 \cdot \log P_{\mathrm{CO}_{2}}
$$

Based on the laboratory-based empirical data, we obtained a correlation equation for predictive assessment of the CDC rate [40]:

$$
\mathrm{CR}=0.028663 \cdot M+0.0238 \cdot T-0.1467
$$

Where:

$M-$ Mineralization, $\mathrm{g} / \mathrm{dm}^{3}$;

$T$ - temperature, ${ }^{\circ} \mathrm{C}$.

Table 5 presents the results of corrosion rate calculations using various predictive models.

When calculating the corrosion rate according to equation (3), the CDC rate does not strongly depend on the shear stress, but mainly depends on the change in the medium temperature: a decrease in temperature by 3 times results in 10 times corrosion rate reduction. Equations (4) and (5) used to estimate the corrosion rate showed that the temperature of the transported medium does not affect the corrosion rate. Evaluation of the corrosion rate according to equations 6 and 7 showed that similar results are obtained at elevated temperatures, whereas at lower temperatures there is some divergence in the corrosion rate values (by 2-4 times). Since the results obtained by equation (4) are overestimated, they were excluded from further analysis.

Table 5. Corrosion rates (mm/year) calculated by different equations and shear stress methods.

\begin{tabular}{cll}
\hline Calculation of shear stress & Flow line & Gas collector \\
\hline method 1 & equation $(3)$ & \\
method 2 & $2.0-45.9$ & $0.65-2.9$ \\
method 3 & $1.5-38.8$ & $0.5-2.5$ \\
\hline
\end{tabular}


equations (4) and (5)

\begin{tabular}{ccc}
\hline method 1 & $0.47-1.7$ & $0.058-0.096\left(0.101^{*}\right)$ \\
method 2 & $0.57-2.2$ & $0.074-0.124\left(0.101^{*}\right)$ \\
method 3 & $0.45-1.5$ & $0.065-0.107\left(0.101^{*}\right)$ \\
\hline \multicolumn{3}{c}{ equation $(6)$} \\
\hline- & $0.31-3.1$ & $0.11-0.49$ \\
\hline- & equation $(7)$ & $0.55-1.18$ \\
\hline- & $0.95-2.3$ & Gravimetric test data \\
\hline
\end{tabular}

*The results are calculated using the equation (5)

The calculated corrosion rates were compared with the practical results (gravimetric data) obtained by the authors in simulation tests for the corrosive conditions of offshore fields. As can be seen from Table 5, the calculated CDC rates obtained by equations (5) and (6) at elevated temperatures $\left(60-80^{\circ} \mathrm{C}\right.$, flow line) are lower than the gravimetric test data. At lower temperatures $\left(20-30^{\circ} \mathrm{C}\right.$, gas collector), the calculated data are either slightly lower or higher than the corrosion rate obtained during simulation tests. At low temperatures $\left(5^{\circ} \mathrm{C}\right.$ and below), the calculated and gravimetric results have rather low corrosion rates (0.1-0.2 mm/year). Comparison of the results obtained by the equations (7) and (8) with gravimetric data (Figure 3) outlines that $1.6 \mathrm{~mm} /$ year $\left(60-80^{\circ} \mathrm{C}\right)$ stays within the range of calculated corrosion rates $0.31-3.1 \mathrm{~mm} /$ year (equation (7)) and $0.95-2.3 \mathrm{~mm} /$ year (equation (8)). The gravimetric value of the corrosion rate of $0.76 \mathrm{~mm} /$ year obtained at $20-30^{\circ} \mathrm{C}$ more accurately coincides with the range of $0.55-1.18 \mathrm{~mm} / \mathrm{year}$ (equation (8)).

\section{Conclusions}

The presence of glycol in a liquid can have a different effect on corrosion processes depending on the concentration of MEG, the type of corrosion (TOL and BOL). The presence of MEG reduces the corrosiveness of an aqueous medium and the solubility of aggressive $\mathrm{CO}_{2}$ for $\mathrm{BOL}$ corrosion media. The determining factor in the development of TOL corrosion is the presence of a large amount of water, which leads to an increase in local corrosion damage up to 1-3 mm/year. As for TOL corrosion tests, the most crucial factor is a MEG content in the condensate water on steel, not in the evaporated liquid. When the MEG content in water is from $75 \%$ and higher, the aggressiveness of TOL corrosion decreases due to an increase in the MEG concentration in the condensed water, which greatly reduces CDC and leads to the termination of its localization.

A comparative analysis of several predictive models highlighted that their use to determine the corrosion rate can be limited for the conditions of offshore fields. Real internal 
corrosion rates from simulation tests are lower, than those calculated with the use of some models.

The use of corrosion inhibitors and the engineering of an inhibitor protection system is one of the rational ways to ensure corrosion protection of offshore fields.

\section{References}

1. R.R. Kantyukov, D.N. Zapevalov and R.K. Vagapov, Hazard Assessment of the Internal Carbon Dioxide Corrosion of the Field Pipelines at the Gas and Gas Condensate Fields, Bezopasnost' Truda v Promyshlennosti, 2021, 2, 56-62. doi: 10.24000/0409-29612021-2-56-62

2. Y. Bai and Q. Bai, Subsea pipeline integrity and risk management, Gulf Professional Publishing, 2014, p. 428.

3. N.A. Makhutov, A.M. Lepikhin and V.V. Leshchenko, Scientific and methodological provision of safety of subsea pipelines with defects using risk criteria, Industrial laboratory. Diagnostics of materials, 2021, 87, 45-53. doi: 10.26896/1028-6861-202187-6-45-53

4. B. Singh, D. Flanery and J.N. Britton, Offshore Corrosion Failure Analyses - A Series of Case Histories, Corrosion (NACE), 2003, paper 03114.

5. D.N. Zapevalov and R.K. Vagapov, Analysis of regulatory requirements for the assessment of carbon dioxide corrosion at gas production facilities, Issues of Risk Analysis, 2021, 18, 60-71. doi: 10.32686/1812-5220-2021-18-2-60-71

6. S. Hasana, L. Sweetb, J. Hultsa, G. Valbuenab and B. Singha, Corrosion risk-based subsea pipeline design, Int. J. Pressure Vessels Piping, 2018, 159, 1-14. doi: 10.1016/j.ijpvp.2017.10.003

7. D. Zapevalov and R. Vagapov, Aspects of protection against carbon dioxide corrosion of gas production facilities, E3S Web of Conferences, 2019, 121, Article 02013. doi: 10.1051/e3sconf/201912102013

8. V.E. Petrenko, M.F. Nuriev, M.B. Shevelev, Yu.V. Semenov, R.A. Shologin and V.Yu. Motovilov, Experience of development and reservoir engineering at off-shore field equipped with subsea production units in the Russian Federation, Gas Industry of Russia, 2018, 777, 8-13.

9. A. Halvorsen, T. Andersen, E. Halvorsen, G. Kojen, J. Skar, C. Biørnstad and H. Fitje, The relationship between internal corrosion control method, scale control and meg handling of a multiphase carbon steel pipeline carrying wet gas with $\mathrm{CO}_{2}$ and acetic acid, Corrosion (NACE), 2007, paper 07313.

10. A. Wilhelmsen, H.C. Meisingset, S. Moxnes and H.O. Knagenhjelm, Ormen Lange-1: Extreme subsea conditions drive concept development, Oil Gas J., 2005, 103, 62-67.

11. O. Hagerup and S. Olsen, Corrosion Control by pH Stabilizer, Materials and Corrosion Monitoring in $160 \mathrm{~km}$ Multiphase Offshore Pipeline, Corrosion (NACE), 2003, paper 03328. 
12. D. Zapevalov and R. Vagapov, Possibilities and limitations of the organization of anticorrosion protection at gas production facilities, E3S Web of Conf., 2021, 225, Article 03002. doi: $10.1051 / \mathrm{e} 3$ sconf/202122503002

13. D.E. Powell, Integrity Management for Piggable and Non-Piggable Subsea Pipelines, Corrosion (NACE), 2008, paper 51300-08135.

14. S. Guo, F. Farelas and M. Singer, Effect of monoethylene glycol on sweet top of line corrosion, Corrosion (NACE), 2016, paper 7891.

15. D.V. Klyzhko, D.V. Kutovoy and M.A. Pogosov, Features of operation of the kirinskoe gas-condensate field using monoethylene glycol as an inhibitor of hydration, Gas Industry of Russia, 2019, 782, 22-28.

16. E. Gulbrandsen and J-H. Morard, Why does glycol inhibit $\mathrm{CO}_{2}$ corrosion, Corrosion (NACE), 1998, paper 98221.

17. S. Olsen, O. Lunde and A. Dugstad, pH-stabilization in the Troll gas-condensate pipelines, Corrosion (NACE), 1999, paper 99019.

18. A.A. Olajire, Corrosion inhibition of offshore oil and gas production facilities using organic compound inhibitors - A review, J. Mol. Liq., 2017, 248, 775-808. doi: 10.1016/j.molliq.2017.10.097

19. M.R. Gregg, A. Sharp and K. Bartrip, Corrosion inhibitor developments for offshore gas gathering systems on Canadas Atlantic coast, Corrosion (NACE), 2003, paper 03332.

20. R. Barker, X. Hu, A. Neville and S. Cushnaghan, Inhibition of flow-Induced Corrosion and Erosion-Corrosion for Carbon Steel Pipe Work from an Offshore oil and Gas Facility, Corrosion, 2013, 69, 193-203. doi: 10.5006/0422

21. M.R. Gregg and S. Ramachandran, Review of Corrosion Inhibitor Developments and Testing for Offshore Oil and Gas Production Systems, Corrosion (NACE), 2004, paper 04422.

22. M. Singer, Study of the Localized Nature of Top of the Line Corrosion in Sweet environment, Corrosion, 2017, 73, 1030-1055. doi: 10.5006/2222

23. R. Vagapov, Top-of-line corrosion in the presence of carbon dioxide for gas production facilities, E3S Web of Conf., 2021, 225, 01002. doi: 10.1051/e3sconf/202122501002

24. J.R. Piccardino, M. Stuvik, Y. Gunaltun and T. Pornthep, Internal Inspection of Wet Gas Lines Subject to Top of the Line Corrosion, Corrosion (NACE), 2004, paper 04354.

25. Y. Chen, L. Zhang, H. Qin, L. Xu and M. Lu, Effects of Temperature on $\mathrm{CO}_{2}$ Top of Line Corrosion of Pipeline Steel, Corrosion (NACE), 2011, paper 11327.

26. R.K. Vagapov and D.N. Zapevalov, Corrosion Activity of Operating Conditions for the Steel Equipment and Pipelines in the Plants Extracting $\mathrm{CO}_{2}$-Containing Gases, Metallurgist, 2021, 65, 50-61. doi: 10.1007/s11015-021-01132-x

27. S.L. Asher, W. Sun, R. Ojifinni, J. Pacheco, C. Li, J. Nelson and S. Ling, Top of the Line Corrosion Prediction in Wet Gas Pipelines, Corrosion (NACE), 2012, paper 00013032012 CP. 
28. R.K. Vagapov, K.A. Ibatullin and D.N. Zapevalov, Corrosion Processes on Steel under Conditions of Moisture Condensation and in the Presence of Carbon Dioxide, Chem. Pet. Eng., 2020, 56, 673-680. doi: 10.1007/s10556-020-00825-5

29. W. Li, B.F.M. Pots, B. Brown, K.E. Kee and S. Nešić, A direct measurement of wall shear stress in multiphase flow - Is it an important parameter in $\mathrm{CO}_{2}$ corrosion of carbon steel pipelines?, Corros. Sci., 2016, 110, 35-45. doi: 10.1016/j.corsci.2016.04.008

30. M. Di Bonaventura, B. Brown, S. Nešić, M. Singer, Effect of Flow and Steel Microstructure on the Formation of Iron Carbonate, Corrosion (NACE), 2018, paper 11179.

31. B. Wang, L. Zhang, G. Chen, Q. Li, W. Chang, H. Yao, Y. Liu and Y. Zhang, Corrosion inhibitor film stability under high gas velocity conditions of subsea wet gas, Corrosion (NACE), 2017, paper 9247.

32. NORSOK M-506. $\mathrm{CO}_{2}$ corrosion rate calculation model.

33. T. Villette, A. Traidia, S. Papavinasam and A.M. El-Sherik, Evaluation of an empirical model to predict maximum pitting corrosion rate in wet sour crude transmission pipelines, The J. of Pipeline Engineering, 2018, 17, 117-126. doi: 10.28999/2541-95952019-9-4-444-451

34. S. Nešić, A. Kahyarian and Y.S. Choi, Implementation of a Comprehensive Mechanistic Prediction Model of Mild Steel Corrosion in Multiphase Oil and Gas Pipelines, Corrosion, 2019, 75, 274-291. doi: 10.5006/3093

35. C. Simpson, H. Thomson, D.M. Frigo, G.M. Graham and R. Stalker, Assessing Corrosion Risk and Selection of Appropriate Testing Programs for Gas and GasCondensate Pipelines, Corrosion (NACE), 2017, paper 9713.

36. S. Ramachandran, S. Mancuso and Y.S. Ahn, Test protocol guides selection of wet-gas corrosion inhibitor, Oil Gas J., 2006, 104, 66-74.

37. S. Papavinasam, R. Venkatesan and S. Mudian, Are You Leading Corrosion Control or Following Corrosion?, Corrosion (NACE), 2019, paper 12879.

38. W.P. Jepson, C. Kang, M. Gopal and S. Stitzel, Model for sweet corrosion in horizontal multiphase slug flow, Corrosion (NACE), 1997, paper 11.

39. C.D. Waard, U. Lotz and D.E. Milliams, Predictive model for $\mathrm{CO}_{2}$ corrosion engineering in wet natural gas pipelines, Corrosion, 1991, 47, 976-985.

40. R.K. Vagapov, A.Yu. Prokopenko and I.S. Tomsky, Assessment of the steel corrosion rate at the infrastructure facilities of hydrocarbon deposits as a function of the mineralization and temperature, Industrial laboratory. Diagnostics of materials, 2021, 87, 41-44. doi: 10.26896/1028-6861-2021-87-6-41-44 